Article

\title{
Effective Combustion of Glycerol in a Compression Ignition Engine Equipped with Double Direct Fuel Injection
}

\author{
Michal Gruca, Michal Pyrc, Magdalena Szwaja (D) and Stanislaw Szwaja * (D) \\ Institute of Thermal Machinery, Faculty of Mechanical Engineering and Computer Science, \\ Czestochowa University of Technology, Dabrowskiego 69, 42-200 Czestochowa, Poland; \\ gruca@imc.pcz.czest.pl (M.G.); pyrc@imc.pcz.czest.pl (M.P.); magdaszw24@gmail.com (M.S.) \\ * Correspondence: szwaja@imc.pcz.czest.pl; Tel.: +48-885-840-483
}

Received: 4 October 2020; Accepted: 28 November 2020; Published: 1 December 2020

check for updates

\begin{abstract}
The paper presents results from an investigation focused on toxicity content in the exhaust gases emitted by an internal combustion compression ignition engine fueled with glycerol-ethanol blends at ratio of $50 / 50 \%$ by volume. The innovative issue of this engine is the application of two high pressure injectors for injecting both glycerol-ethanol blend and diesel pilot fuel at high pressure (over $200 \mathrm{MPa}$ ). As known, glycerol is considered a byproduct from biodiesel production technologies, hence its cost is relatively low compared to other renewable alternative fuels which can be applied as fuels to the reciprocating piston engines. It was found that the toxic components $\mathrm{UHC}, \mathrm{NOx}$ and $\mathrm{CO}$ were below the maximum allowed limits. Both NOx and smoke emissions were strongly reduced with increasing glycerol-ethanol fraction in the fuel. Summarizing, a fueling strategy such as that proposed in this paper makes it possible to effectively and environmentally friendly combust crude glycerol in compression ignition engines working in a heat and power cogeneration unit. Exhaust gas emission tests conducted in this case confirmed the usability of this technology to be implemented into practice.
\end{abstract}

Keywords: glycerol; combustion; internal combustion engine; exhaust emission; injection system

\section{Introduction}

One of potential energy sources in the nearest future might be glycerol and its derivatives. Currently, there is a significant surplus of glycerol coming from biodiesel production technologies, where it is the major byproduct. As Presciutti et al. [1] have stated, glycerol's poor lower heating value (LHV) and its ineffective combustion have reduced interest in using it as a fuel. However, they provide promising future premises for glycerol, conclusing that glycerol fed oxy-combustion avoids acrolein production. Additionally, energy production from glycerol improves the biodiesel supply chain sustainability. Brock et al. [2] proposed to use glycerol indirectly in the forms of its derivatives for combustion machinery. In general, researchers have confirmed that glycerol has significant potential as a fuel for thermal machinery [3,4].

\subsection{Glycerol Properties}

Glycerol is a major byproduct from the production of biodiesel from vegetable oils. It yields an amount equivalent to $12 \%$ of the original feedstock. As reported, the global production of crude glycerol in 2020 is predicted at amount of 4200 ML [5]. Hence, glycerol prices have dropped approximately six times in the decade 2000-2010. Glycerol features a relatively low heat of combustion (it is approximately twice lower of that of fossil fuels). It is highly viscous, hence, it causes difficulties in effective spraying 
and atomization when injected into the engine cylinder. Additionally, it has high auto-ignition temperature (nearly $643 \mathrm{~K}$ ) that can limit its usage for compression ignition engines. The physical specifications of glycerol is shown in Table 1.

Table 1. Glycerol main physical properties [6-9].

\begin{tabular}{lccc}
\hline & Property & Unit & Number \\
\hline 1. & Higher heating value (HHV) & $\mathrm{MJ} / \mathrm{kg}$ & 18 \\
2. & Lower heating value (LHV) & $\mathrm{kJ} / \mathrm{mol}$ & 1662 \\
3. & Dynamic viscosity at $25^{\circ} \mathrm{C}$ & $\mathrm{Ma} \cdot \mathrm{s}$ & 16 \\
4. & Kinematic viscosity at $25^{\circ} \mathrm{C}$ & $\mathrm{m}^{2} / \mathrm{s}$ & $(450-750) \times 10^{-6}$ \\
5. & and $40^{\circ} \mathrm{C}$ & $\mathrm{kg} / \mathrm{dm}^{3}$ & $(350-580) \times 10^{-6}$ \\
6. & Density at $0{ }^{\circ} \mathrm{C}$ & - & 1.26 \\
7. & Cetane number $(\mathrm{CN})$ & $\mathrm{K}$ & $0-10$ \\
\hline
\end{tabular}

The typical composition of glycerol produced from biodiesel manufacturing technologies is presented in Table 2 [6-9].

Table 2. Typical composition of technical glycerol [6-9].

\begin{tabular}{ccc}
\hline & Component Content & $\mathbf{\%}(\mathbf{k g} / \mathbf{k g})$ \\
\hline 1. & Glycerol & $70-75$ \\
2. & Water & $14-17$ \\
3. & Mineral content (ash) & $6-8$ \\
4. & MONG (other organic compounds except glycerol) & 5 \\
5. & Methanol & $<1$ \\
\hline
\end{tabular}

\subsection{Combustion Applications}

A number of studies have investigated the combustion of glycerol in a burner with the possibility of application in heating and power boilers [1,10-14].

Presciutti et al. [1] proposed oxy-combustion of glycerol to increase the flame temperature, hence to completely burn it. Zhu [10] investigated glycerol co-combustion with biochar. He found that addition of glycerol significantly reduces ignition delay time, shortens burnout time and increases the burning rate of the droplets. Bohon [12] and Roberts [13] conducted an investigation on fossil fuel replacement by crude glycerol in heat and power plants. Roberts concluded that the combustion of crude glycerol could result in a significant reduction of NOx emissions as a function of the high chemically bound oxygen content in glycerol fuel. His conclusions also showed that the cost of replacing natural gas with crude glycerol is a strong function of the market price per unit of energy for traditional fuel. Bohon and Roberts also noticed that alkali metal content in crude glycerol presents a significant issue that needs to be addressed before crude glycerol can be utilized in boilers. Coronado et al. [14] at his work discussed the ecological aspects of glycerol combustion in industrial boilers. Coronado found glycerol as a better alternative fuel in comparison to diesel fuel, fuel oil, natural gas, and LPG from an ecological point of view. He also stated that burning unblended methylated glycerol has the lowest ecological efficiency, even less than diesel fuel. Queiros et al. [11] tested the combustion of crude glycerol with gaseous fuels: natural gas and hydrogen. Glycerol was sprayed by two typical air assisted atomizers under non-reacting conditions in a laboratory furnace fired by a swirl burner. He obtained results that showed the spray fineness for both atomizers increased with the atomizing air to glycerin mass ratio up to $1, \mathrm{CO}$ and $\mathrm{HC}$ emissions were reduced with glycerol ratio increased up to 1.5 and NOx emission increased as well. Finally, he concluded that acrolein emissions were undetectable for all flames studied. Samoilov et al. [15] worked on glycerol oxygenated derivatives as additives to gasoline to improve its physical properties. As they wrote, glycerol-derived oxygenates decreased the vapor 
pressure of the gasoline and increased its boiling point. To compensate for this effect, they proposed that base gasoline should be enriched with light fractions in order to achieve the same volatility features. Fatimah et al. [16] discussed the possibilities of upgrading glycerol to solketal to make it easier to work with as a fuel additive.

Summing up, there are several papers showing that combustion of crude glycerol is an inconvenient process due to the following factors: its low heating value, high self-ignition temperature, acrolein formation, high toxic emissions and high salt content $[14,17,18]$. Additionally, the high toxicity to the natural environment of the exhaust emissions from its combustion, as reported by Rodrigues et al. [17], is a challenge which has motivated researchers to work out an effective method that can be implemented in glycerol-fueled combustion units for heat and power generation. Gupta and Kumar [5] stated that formation of acrolein as a harmful product of glycerol combustion can be reduced significantly by high temperature combustion. Except for direct combustion and the solid fuel method, all the other pathways require purification of the crude glycerol. Despite these problems, research is being conducted to develop an effective combustion technology that will be characterized by low exhaust gas toxicity.

\subsection{Combustion in the Internal Combustion Engine}

Several important problems were reported by researchers working on applying glycerol as an substitute engine fuel. Among others, Stenhede [18] from the company Wärtsilä, stated that glycerol cannot be effectively burnt in the diesel engine due to problems with its self-ignition. Hence, the research team from Wärtsilä has attempted glycerol combustion using diesel fuel pilot dosing. There are other papers which state that glycerol is a poor fuel which does not burn in either spark ignited or compression ignition engines $[19,20]$. Another group of researchers (Oprescu et al. [21]) proposed glycerol processing and burning its derivatives as additives in blends with classic fossil fuels. Eaton et al. [22] investigated the combustion of glycerol in a diesel fueled engine. They used diesel fuel-glycerol mixtures containing 10 and $20 \%$ glycerol. They reported problems with mixture stability, so they had to use ultrasonic blending to obtain glycerol-diesel emulsions. They also found nitrogen oxides and particulate matter (PM) emissions were reduced by $5-15$ and $25-50 \%$, respectively. The indicated fuel consumption increased, corresponding to the increase of glycerol content in the fuel because of a reduction in the emulsion energy density. Thermal efficiency improvements were observed at high loads. Beatrice et al. [23] worked on applying glycerol ethers in diesel as oxy-fuel for automotive engines. They stated that the use of glycerol derivatives as additives in neat diesel reduced the flash point of the blends. They tested blends containing 10 and $20 \%$ glycerol ethers by volume. They found the glycerol ethers added to neat diesel fuel affected the combustion process, mainly at low engine load through the low cetane number $(\mathrm{CN})$ of these ethers. They also found that glycerol ethers are effective for particulate matter (PM) emission suppression. PM reduction is accompanied by a reduction of emitted engine raw particles. They also recommended continuing work on real engine exhaust emissions to evaluate the impact of glycerol ether additives on unregulated tailpipe emissions. Munsin and his group [24] conducted research on applying glycerol at small amounts up to $5 \%$ to ethanol fuel for spark ignited engines. They found that glycerol improves the ignition process and decreases injection rates by approximately $10 \%$ with respect to normal hydrous ethanol. McNeil [25] realized an investigation applying glycerol as fuel in compression ignition engines. He and his team developed a combustion cycle that permits utilization of glycerol without the need for diesel fuel pilot or cetane-improving additives. Their idea was to heat up the intake air to a temperature of $144{ }^{\circ} \mathrm{C}$, which was optimal for that engine type when burning glycerol.

Striving to improve the performance, mainly the performance of the reciprocating internal combustion engine, has always been the overriding goal of several industrial and academic research centers. This article describes how to effectively deliver hardly flammable fuels (e.g. glycerol) to an IC engine with the aid of two high pressure injectors. After testing, the system was used to burn mixtures of raw glycerol and ethanol. At the outset, it should be mentioned that the high pressure 
direct injection system with two independently working injectors is a solution that is relatively difficult to implement in practice. These difficulties mainly come from small and limited space in engine cylinders in which the additional injector could be mounted. Hence, such solutions are used for large engines. For this reason, i.e., due to the lack of space for a second injector, such solutions are not used in automotive engines found in cargo and passenger transport drive systems. Another reason is the economy of such a solution. The use of two injectors working independently increases the engine manufacturing cost. Hence, there is no need for such a solution in the case of single-fuel engines or so-called dual-fuel ones, i.e., engines fueled with two fuels, where the main fuel is natural gas, and the second is diesel fuel used to initiate the ignition and combustion process. The need to use a system equipped with two independently controlled injectors arose in the case of attempts to use glycerol as a fuel for the internal combustion piston engine. Several research works [26,27] by Chwist et al. and Grab-Rogalinski et al. were realized in this field. They tested various hardly flammable liquids including glycerol as fuels in both the spark ignited CFR engines with variable compression ratios and compression ignition engines equipped with double high pressure injection systems. They confirmed that raw glycerol requires warming up to nearly $90^{\circ} \mathrm{C}$ prior to being injected into the intake port. It turned out that the method applying two independently working direct injectors enabled injection and combustion of large doses of glycerol. Thus, it enables the use of glycerol as the main fuel for the engine. The second injector is used for the injection of a diesel fuel pilot dose, which is used to initiate ignition and, consequently, combustion of glycerol.

Summarizing, currently conducted research on combustion of glycerol in reciprocating piston engines deals with combustion of small amounts of glycerol (up to several percent by volume) mixed with another fuel $[22-24,28]$. Such a mixture can be injected into the engine intake manifold or directly into the cylinder.

The main objective of the research presented here is to confirm that combustion of glycerol at high amounts in the IC engine can be energetically effective and environmentally friendly with application of double direct injection systems. It can be concluded from the literature survey that such a method of using the system consisting of two high pressure injectors to feed the engine and burn glycerol has not been tested so far. Hence, this research can be considered an innovative research work from this point of view.

\section{Research Methodology}

The methodology arrangements for the research work presented in this article were focused on the following:

- To obtain knowledge on glycerol combustion under compression ignition conditions with diesel fuel pilot for combustion initiation. As glycerol features relatively high viscosity, ethanol was proposed to dilute it that results in a decrease of its kinematic viscosity.

- To obtain knowledge on the toxicity of the engine exhaust gases. Hence, the tests were focused on emissions of the following toxic exhaust gases: NOx, CO, UHC and smoke.

- To test the dual fuel injection system with two independently working high pressure injectors for diesel fuel pilot and glycerol-ethanol, respectively, mounted in the engine cylinder.

\subsection{Parameters Varied}

On a basis of the objectives presented above, studies in this field were concentrated on influence of various ratio between glycerol-ethanol blend $(G+E)$ and diesel fuel $(D F)$ on exhaust gases toxic emission.

The fraction of $(G+E)$ mixture in the total fuel injected into the cylinder was defined as fraction by energy. Hence, energy fraction of glycerol-ethanol $(G+E)$ in entire fuel dose was determined with Equation (1):

$$
\text { Energy Fraction }(G+E)=\frac{G+E}{G+E+D F}
$$


where:

$$
\begin{gathered}
G=m_{G} L H V_{G}, \\
E=m_{E} L H V_{E}, \\
D F=m_{D F} L H V_{D F},
\end{gathered}
$$

where $m_{G}, m_{E}, m_{D F}$-mass of glycerol in the glycerol-ethanol mixture, mass of ethanol in this mixture, mass of diesel fuel pilot dose, per single combustion event, respectively, and $L H V_{G}, L H V_{E}$, $L H V_{D F}$-lower heating value of: glycerol, ethanol and diesel fuel, respectively.

The fuel specifications are presented in Table 3.

Table 3. Fuel specifications.

\begin{tabular}{cccccc}
\hline Parameter & Unit & Glycerol & Ethanol & G + E (50/50) & Diesel Fuel \\
\hline LHV & $\mathrm{MJ} / \mathrm{kg}$ & 20.3 & 33.4 & 25.8 & 42.5 \\
\hline $\begin{array}{c}\text { Density at NTP } \\
\begin{array}{c}\text { Kinematic } \\
\text { viscosity at } 40{ }^{\circ} \mathrm{C}\end{array}\end{array}$ & $\mathrm{kg} / \mathrm{dm}^{3}$ & 1.248 & 0.785 & 1.016 & 0.825 \\
\hline
\end{tabular}

As mentioned, the total energy in the glycerol-ethanol blend and diesel fuel pilot dose per single combustion event was maintained constant. It was achieved with diesel fuel pilot dose varied from 9.5 to $22 \mathrm{mg} / \mathrm{cycle}$, whereas, the glycerol-ethanol dose varied from 133 to $95 \mathrm{mg} / \mathrm{cycle}$ at the same time. As shown in Figure 1, the energy fraction of $(G+E)$ blend in the total fuel dose was varied from 0.67 to 0.96 , whereas the diesel fuel fraction was changed from 0.33 to 0.05 , respectively.

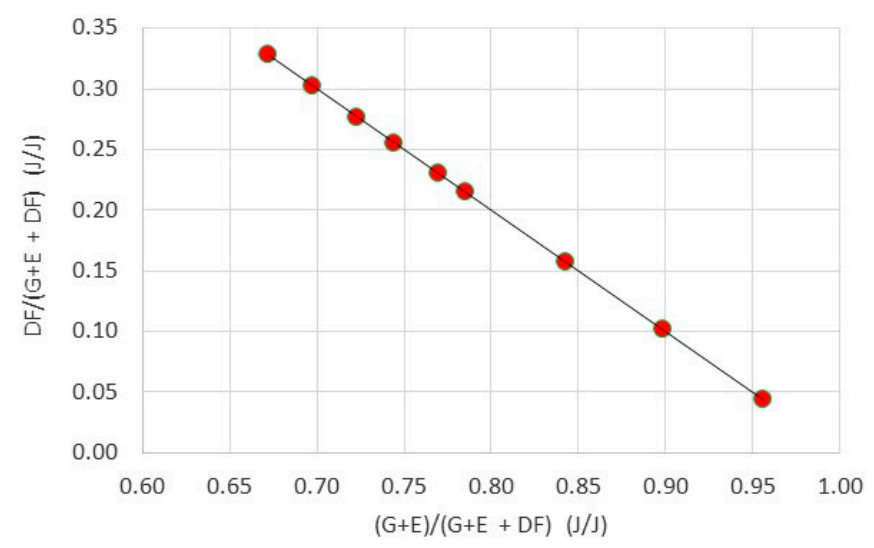

Figure 1. Correlation between DF fraction vs. $G+E$ fraction by energy.

Although, both doses were simultaneously changed to maintain constant energy content in the total fuel dose, but for further analysis, the $(G+E)$ fraction was taken as the independent parameter.

The total energy in the entire fuel dose to engine cylinder is presented in Figure 2. As depicted, the total mean energy in both fuel doses $(G+E$ and $D F)$ per single combustion event (cycle) was maintained constant at a level of $2868 \pm 20 \mathrm{~J}$. The condition of constant energy per cycle was assumed with respect of avoiding the influence of variable energy on engine cooling and consequently on in-cylinder peak combustion temperatures. Hence, it appeared simple to determine indicated thermal efficiency as well as find credible correlations between exhaust toxic emissions and $G+E$ fraction in the total fuel dose. 


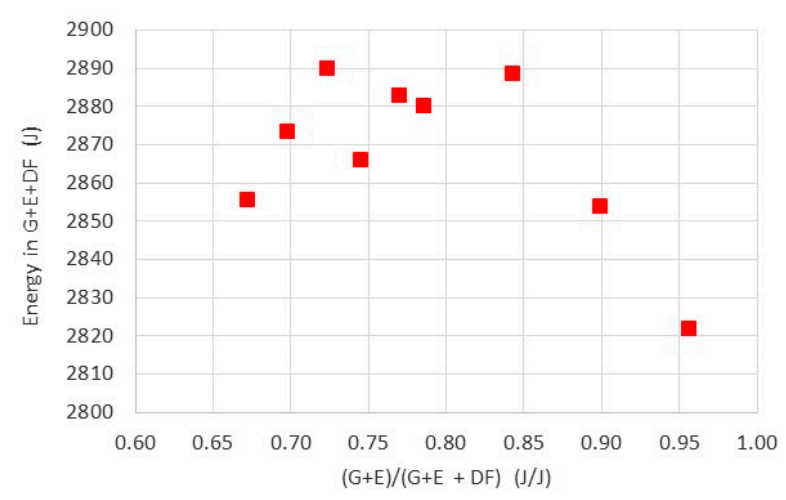

Figure 2. Energy in entire fuel vs. $G+E$ energy fraction.

\subsection{Parameters Maintained Constant}

The following parameters were maintained constant during tests:

- The basic fuel was a mixture of 50\% ethanol and 50\% glycerol by volume. The 50/50 ratio was determined on a basis of maximum injector flowrate capacity under acceptable kinematic viscosity. Hence, the kinematic viscosity varied in narrow range between $3.3 \times 10^{-6}$ and $3.7 \times 10^{-6} \mathrm{~m}^{2} / \mathrm{s}$.

- Engine run at a constant speed of $970 \mathrm{rpm}$. The speed was limited by a belt transmission from the engine to the power generator and synchronous speed of that generator.

- Injection pressures for both injectors were constant and adjusted to 2000 bar. Hence, each fuel dose was precisely regulated by injection timing.

- The entire fuel energy per cycle was constant and it was in the range between 2820 and $2890 \mathrm{~J} / \mathrm{cycle}$, as previously depicted in Figure 2. This condition required simultaneously changing both the glycerol-ethanol and diesel pilot dose. Hence, with an increase of the diesel pilot dose, the glycerol-ethanol dose systematically decreased. It was important to maintain constant the total energy of entire fuel injected into the cylinder in regards to obtaining knowledge on the following: engine overheating, exhaust gases temperature and thermal efficiency.

- Injection timing for the diesel pilot fuel was fixed. Start of injection (SOI) was at 26 CA deg bTDC (before Top Dead Center-bTDC). This optimal SOI for diesel fuel was determined during preliminary tests regarding the highest efficiency of the engine working on diesel fuel only.

- With respect to glycerol-ethanol injection timings, the fixed SOI strategy was applied due to maintaining the same pressure-volume initial conditions at ignition point, that affects total combustion process. As known, combustion products among others depend on combustion initial parameters. Hence, SOI for glycerol-ethanol was fixed at 10 CA deg bTDC. A summary of the operating parameters is presented in Table 4.

Table 4. Test matrix.

\begin{tabular}{lcc}
\hline \multicolumn{1}{c}{ Parameter } & Unit & Value \\
\hline Parameters varied & & \\
\hline $\mathrm{G}+\mathrm{E}$ fraction in total fuel dose & $\mathrm{mg} / \mathrm{cycle}$ & $0.67-0.96$ \\
\hline \multicolumn{1}{c}{$\mathrm{G}+\mathrm{E}$ dose } & $\mathrm{mg} / \mathrm{cycle}$ & $95-133$ \\
\hline \multicolumn{1}{c}{$\mathrm{DF}$ dose } & & $22-9.5$ \\
\hline Parameters maintained constant & $\%$ & $50 / 50$ \\
\hline Glycerol to ethanol ratio & $\mathrm{J}$ & $2820-2890$ \\
\hline Entire fuel dose by energy & $\mathrm{rpm}$ & 970 \\
\hline Engine speed & bar & 2000 \\
\hline Injection pressure for G + E and DF & CA deg bTDC & 26 \\
\hline Start of injection for DF & CA deg bTDC & 10 \\
\hline Start of injection for G+E & & \\
\hline
\end{tabular}




\subsection{Test Bench Description}

Figure 3 presents the complete test bench with the compression ignition engine S320 (2) equipped with the double common rail system $(1,7,9,10,14)$ for independent injection of both the diesel fuel $(D F)$ pilot dose and the mixture of glycerol and ethanol $(G+E)$. The engine specifications are provided in Table 5.

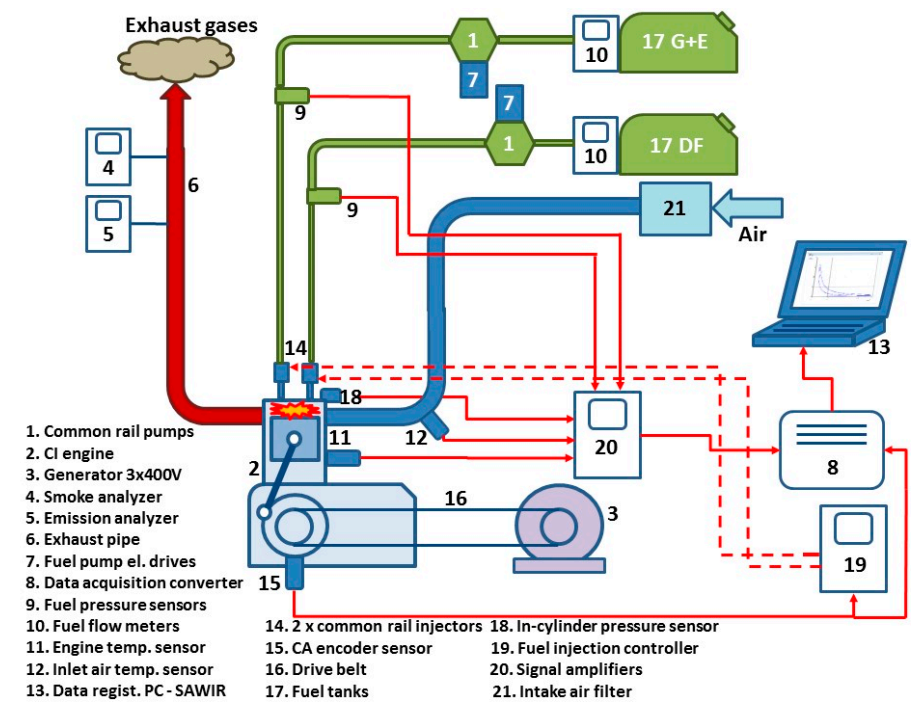

Figure 3. Test bed scheme.

Table 5. Engine main specifications.

\begin{tabular}{cc}
\hline Parameter & Value \\
\hline Type of the engine & Four stroke \\
Number of cylinders & 1 \\
Compression ratio & 17 \\
Engine rotational speed & $970 \mathrm{rpm}$ \\
Displacement & $1810 \mathrm{~cm}^{3}$ \\
Max. injection pressure & $250 \mathrm{MPa}$ \\
Max. rated power & $13.3 \mathrm{~kW}$ \\
Max. engine torque & $104 \mathrm{Nm}$ \\
Bore $\times$ Stroke & $120 \times 160 \mathrm{~mm}$ \\
\hline
\end{tabular}

The look at the engine with the power generator and two electrical motors (No. 7-above the engine) for driving high pressure injection pumps is depicted in Figure 4.

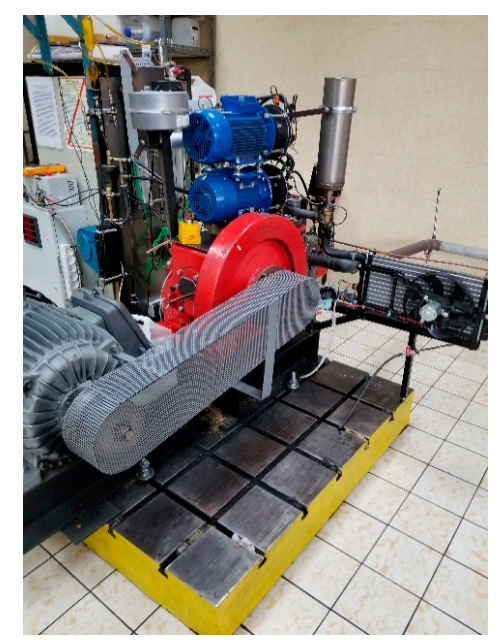

Figure 4. View on the engine at the test bed. 
The double common rail system consists of two parallelly installed feeding lines for liquid fuels. The fuels can be directly injected under high pressure up to $250 \mathrm{MPa}$ into the engine cylinder as depicted in Figure 5. Spraying clouds are developed in the bowl-shaped piston. The original injector location is marked with $G+E$. Nowadays, this injector feeds the engine with glycerol-ethanol blend $(G+E)$. The additional injector, which was used for diesel fuel $(D F)$ was mounted nearby. Although, spraying cloud from the DF injector can reach piston surface due to non-centralized location, but such approach was justified because it only injects diesel pilot dose to initiate combustion of the main $G+E$ fuel.

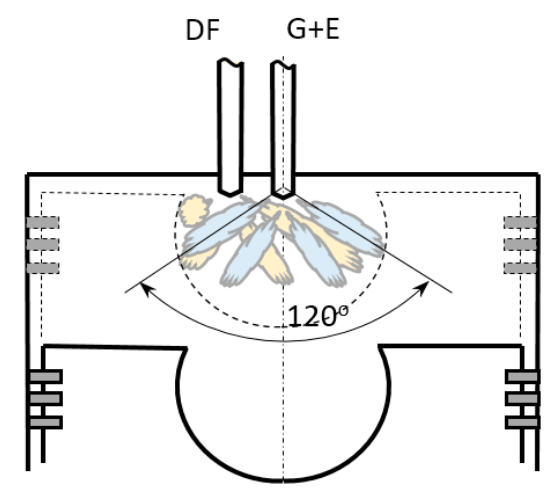

Figure 5. Location of 2 common rail injectors for glycerol-ethanol $(G+E)$ and diesel fuel $(D F)$.

The measurement apparatus consists of the following:

- A 415SE smoke meter from AVL (Graz, Austria) with a measuring range to 10 filter smoke number (FSN) [29];

- A Measurement Computing USB-1608HS-16 bits resolution data acquisition module (Measurement Computing Corporation, Norton, MA, USA), with a sampling frequency of $200 \mathrm{kHz}$;

- A 6061 SN 298131piezo-ceramic pressure transducer (Kistler, Winterthur, Switzerland) with $\pm 0.5 \%$ sensitivity;

- $\quad$ Kistler 5011 charge amplifier with FS < $\pm 0.5 \%$ linearity;

- Crank angle encoder with resolution 1024 pulses/rev,

- MSO2014 signal analysis unit (Tektronix, Beaverton, OR, USA);

- $\quad$ Air/fuel LM-2 with lambda sensor, range 7.35-22.38 (Ratio Meter, Sycamore, IL, USA)

- $\quad$ BEA 350THC, CO, CO 2 gas analyzer (Bosch, Gerlingen, German) (CO, CO 2 and THC are measured based on the NDIR method, while the measuring principle of the oxygen concentration is based on an electrochemical $\mathrm{O}_{2}$ cell).

\subsection{Errors and Accuracies in Tests}

Accuracies in measurements of the crucial parameters are shown in Table 6.

Table 6. Absolute errors and uncertainties of measured parameters.

\begin{tabular}{|c|c|c|c|}
\hline \multicolumn{2}{|c|}{ Measured Parameters } & Absolute Error & Uncertainty (\%) \\
\hline \multicolumn{2}{|c|}{ Rate of flow of diesel fuel } & $0.25 \mathrm{~g} / \mathrm{min}$ & 2.5 \\
\hline \multicolumn{2}{|c|}{ Rate of flow of glycerol/ethanol blend } & $0.25 \mathrm{~g} / \mathrm{min}$ & 0.5 \\
\hline \multicolumn{2}{|c|}{ Dose of diesel fuel } & $0.5 \mathrm{mg} / \mathrm{cycle}$ & 2.5 \\
\hline \multicolumn{2}{|c|}{ Dose of glycerol/ethanol fuel } & $0.5 \mathrm{mg} / \mathrm{cycle}$ & 0.5 \\
\hline \multicolumn{4}{|c|}{ Gas analyser } \\
\hline UHC & range 0-9999 ppm vol & 12 ppm vol & \\
\hline $\mathrm{CO}$ & range $0-10 \%$ vol & $0.4 \%$ vol & \\
\hline $\mathrm{NO}$ & range 0-9999 ppm vol & 10 ppm vol & \\
\hline Smoke & range: $0-10 \mathrm{FSN}$ & $0.002 \mathrm{FSN}$ or $0.02 \mathrm{mg} / \mathrm{m}^{3}$ & \\
\hline
\end{tabular}




\section{Results and Discussion}

As known, in-cylinder temperature is the crucial parameter which affects exhaust toxic emissions, in particular with nitric oxides (NOx). Assuming that both the compression and expansion ratio were fixed as well as valve timing and other parameters influencing the combustion process, one can conclude that the exhaust gas temperature is in close correlation with the average in-cylinder combustion temperature, therefore the temperature Teg of exhaust gases was measured during the experiments. Figure 6 depicts the temperature Teg vs. $G+E$ fraction. As seen, Teg is in an almost linear negative correlation with the glycerol-ethanol energy fraction $(G+E)$ in the total combustible fuel charge $(G+E+D F)$ injected into the engine cylinder. A temperature drop by $80 \mathrm{~K}$ is observed when the $G+E$ energy fraction increased from 0.67 to 0.96 . As long as the energy of the total fuel dose is constant, this temperature drop can be explained by the higher amounts of glycerol and ethanol, that increase the cooling effect from the $G+E$ evaporation process inside the engine cylinder. Thus, it can be stated as a conclusion that both mean and peak in-cylinder combustion temperatures decrease with increasing $G+E$ content, which affects NOx (here determined as only NO) formation following thermal NOx mechanism by Zeldovich [30]. As observed in Figure 7, NOx exhaust emissions go down strongly from nearly 300-400 ppm to below $50 \mathrm{ppm}$ with a $G+E$ increase. Similar NOx emission reduction results were reported by Lapuerta et al. [28], but he worked with smaller amounts of glycerol esters as additives to diesel fuel.

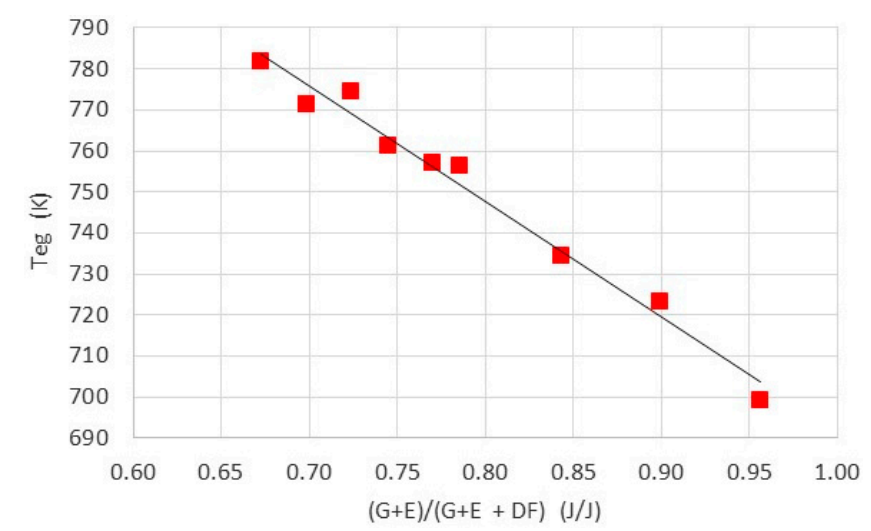

Figure 6. Temperature of exhaust gases vs. $G+E$ fraction by energy content.

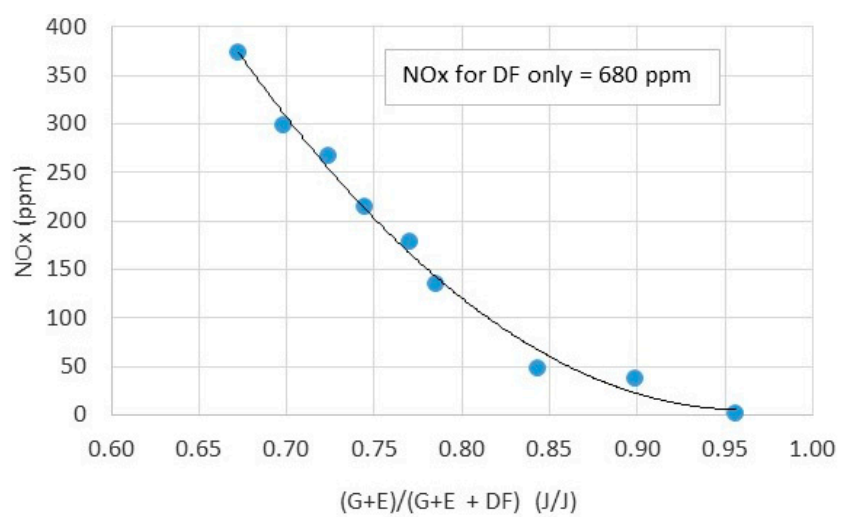

Figure 7. NOx vs. $G+E$ fraction by energy content.

Unlike NOx, unburnt hydrocarbons (UHC) increase lightly and then stabilize at a level of $600 \mathrm{ppm}$ with increase of $G+E$ content in the total fuel dose, as presented in Figure 8. This effect can be considered as a combined effect of two phenomena operating contrary to each other:

- cooling by higher amounts of $G+E$,

- and oxygenation by oxygen bounded in the $G+E$ mixture. 


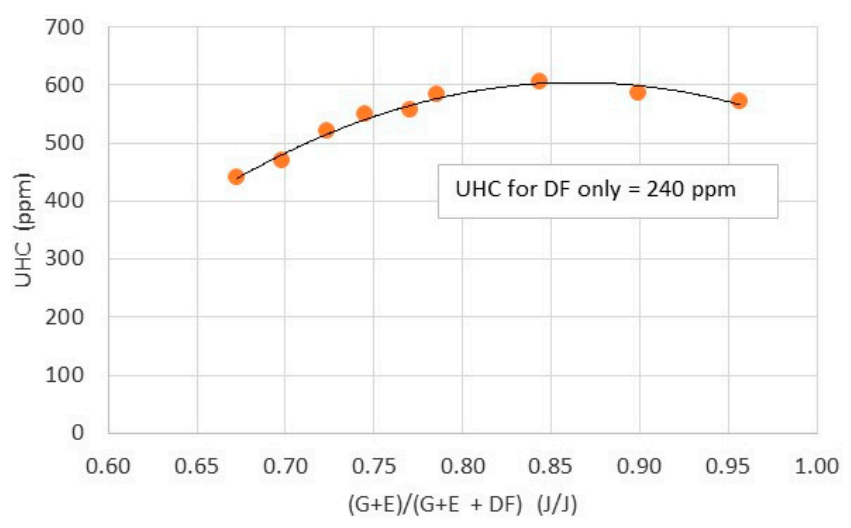

Figure 8. UHC vs. G + E fraction by energy content.

Unfortunately, this explanation does not seem useful in examining the $C O$ trend with $G+E$ increase, as depicted in Figure 9. At first, $\mathrm{CO}$ emission systematically decreases as $G+E$ increases from 0.67 to $0.80-0.85$. If one assumes that $G+E$ is providing additional oxygen and the combustion temperature is still high enough to effectively oxidize $C O$, this conclusion makes sense. When $G+E$ increases over 0.8 then the exhaust temperature rapidly drops below $730 \mathrm{~K}$. Hence, the mean combustion temperature is expected to drop down as well. This temperature drop might cause a rapid increase in $\mathrm{CO}$ even though higher oxygen is provided in the fuel. As known, the chemical reaction rate for $\mathrm{CO}_{2}$ at those temperature ranges is relatively low, therefore higher $\mathrm{CO}$ emissions are expected as a result from a lack of time for complete oxidation $\mathrm{CO}$ to $\mathrm{CO}_{2}$. The total time of the expansion stroke when $\mathrm{CO}$ can be burnt to $\mathrm{CO}_{2}$ inside the engine cylinder is limited to nearly $30 \mathrm{~ms}$ at an engine speed of $970 \mathrm{rpm}$.

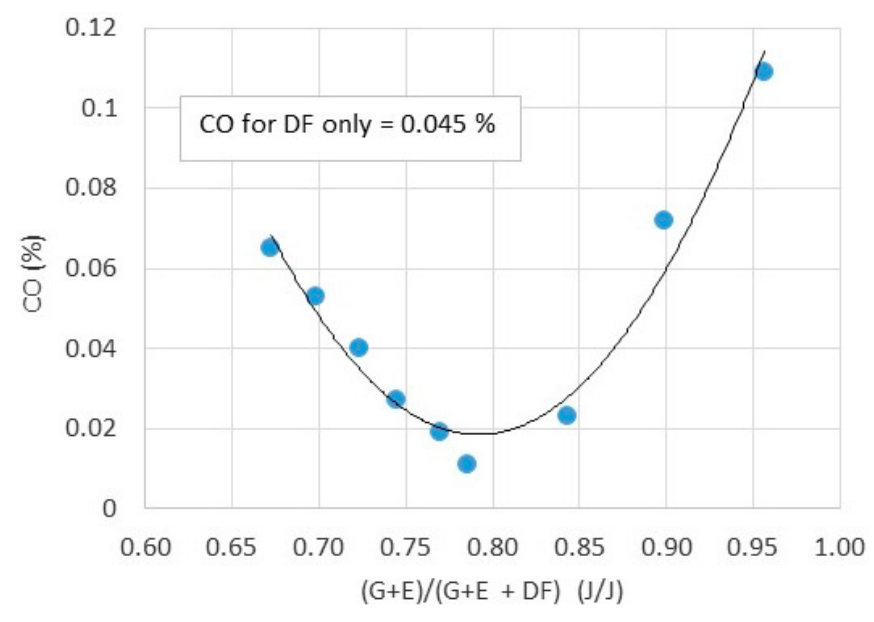

Figure 9. $C O$ vs. $G+E$ fraction by energy content.

Smoke in exhaust gases was measured following the AVL method [28]. This method is based on the mass trapped in a special filter. Thus, smoke in numbers is considered as both soot and PM. As plotted in Figure 10, the smoke trend was negatively correlated with the $G+E$ fraction. Hence, one can conclude that addition of glycerol-ethanol blends to the total fuel charge, that will be burnt in the engine cylinder, remarkably reduces smoke emissions. As the smoke mainly consists of soot in this case, $G+E$ addition reduces soot formation and its content in the exhaust gases as well. To correctly confirm this thesis about this negative smoke trend, additional plots were performed as follows:

- $\quad$ smoke against glycerol-ethanol $(G+E)$ dose by mass (Figure 11),

- $\quad$ and smoke against diesel fuel pilot (DF) dose by mass (depicted in Figure 12). 


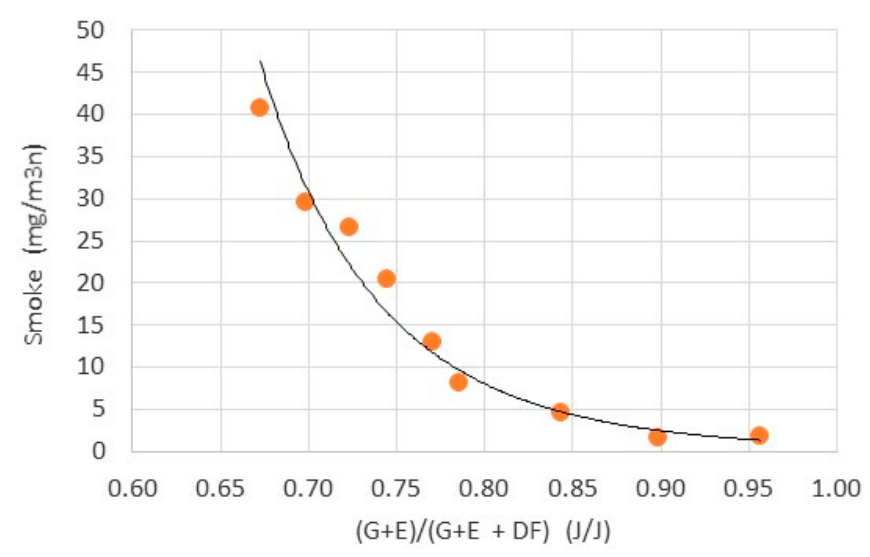

Figure 10. Smoke vs. $G+E$ fraction by energy content.

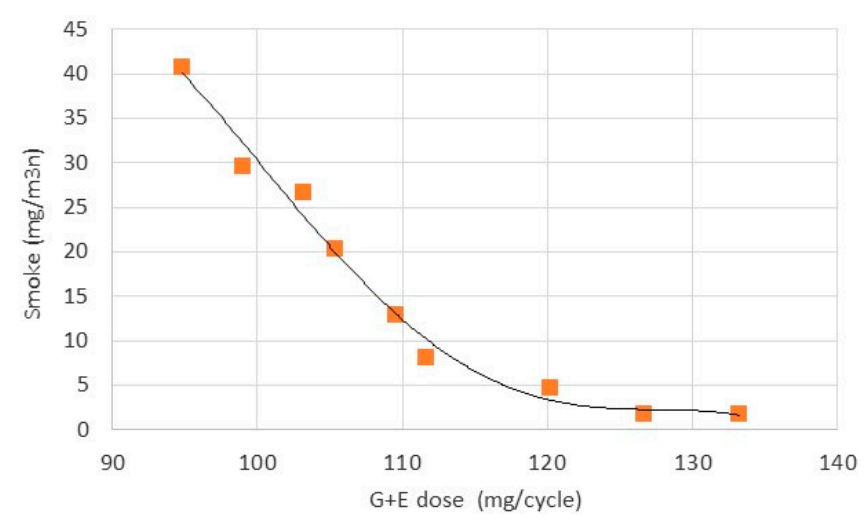

Figure 11. Smoke vs. glycerol-ethanol $(G+E)$ dose.

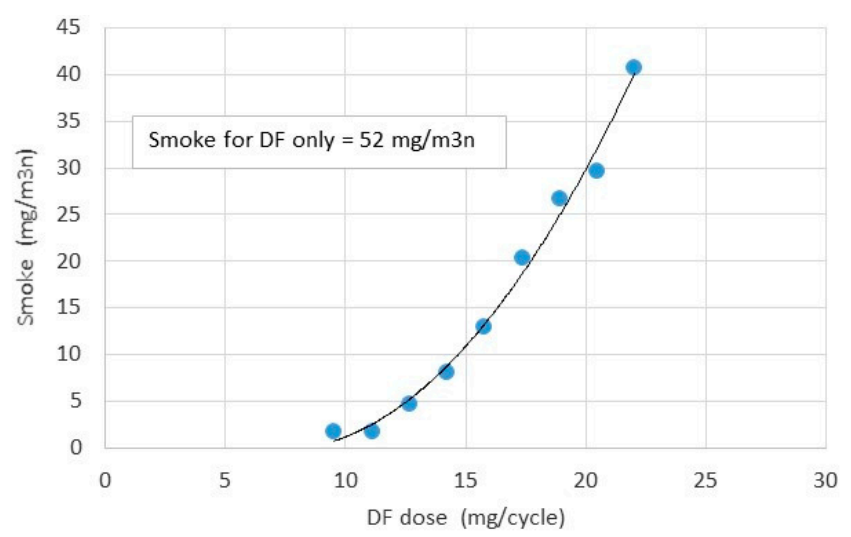

Figure 12. Smoke vs. diesel fuel (DF) pilot dose.

Both $D F$ and $G+E$ dose came from the same tests depicted in Figure 10. The trend showed in Figure 10 is almost perfectly correlated with the trend in Figure 11, presenting smoke vs. $G+E$ dose.

Furthermore, one can conclude that smoke is positively correlated with the amount of diesel fuel in the total fuel charge injected into the cylinder (Figure 12). Hence, the conclusion on smoke emission caused by diesel fuel in the engine working on glycerol-ethanol mixture can be confirmed on the basis of these observations. However, we cannot clearly state which liquid-ethanol or glycerol—influences more significantly the smoke emissions, however, Eaton [22] and Beatrice [23] also confirmed that the addition of glycerol to diesel fuel reduces PM, so does smoke emissions.

Unfortunately, deterioration in engine indicated, thermal efficiency with $G+E$ increase was observed, as presented in Figure 13. Although the combustion was complete and there were not any combustibles in the exhaust gases, the combustion process got lengthened due to decrease in mean combustion temperature. Under fixed injection timings for both doses, the maximum peak 
pressure decreased with an increase in $G+E$ fraction (Figure 14a). To confirm this statement, exemplary plots of in-cylinder pressure and heat release rate (HRR) are depicted in Figure 14. As observed, addition of $G+E$ significantly changes location for the diffusion phase of combustion. It was shifted far from the TDC towards the expansion stroke (Figure 14b). It was the main reason for the drop in indicated efficiency.

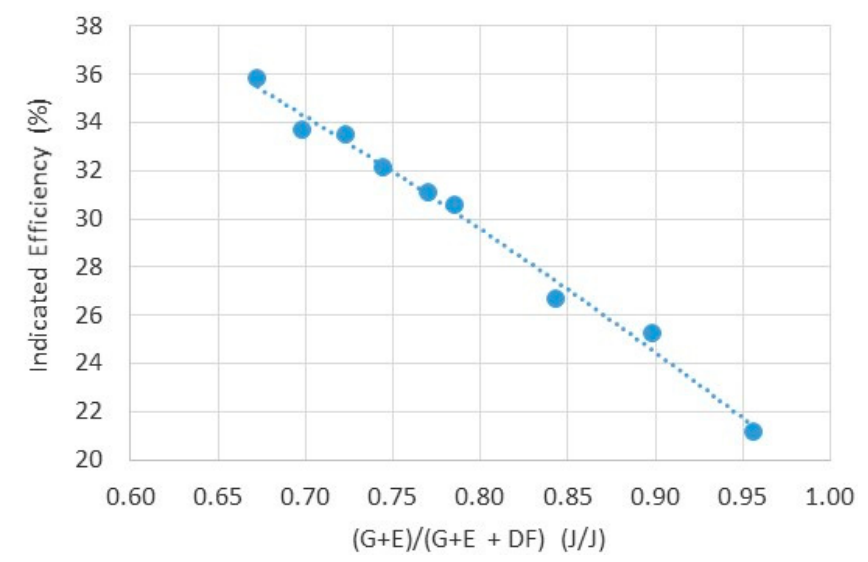

Figure 13. Indicated efficiency vs. $G+E$ fraction by energy content.

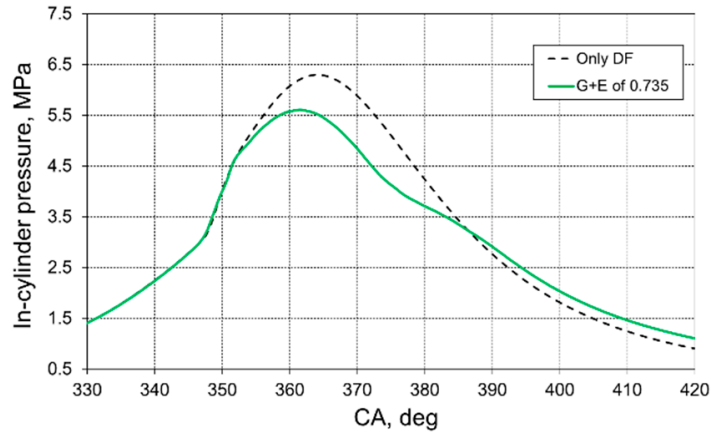

(a)

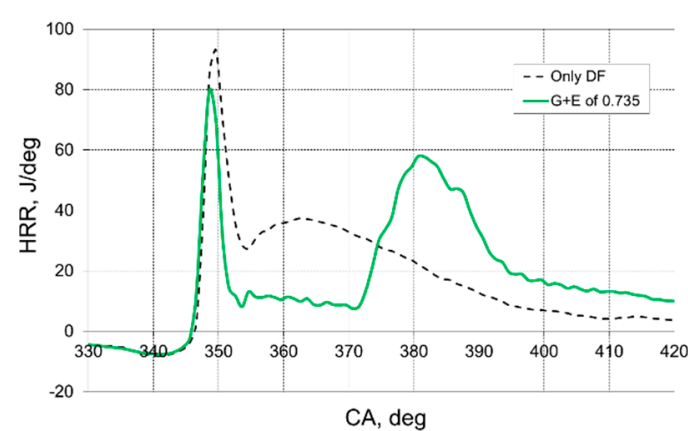

(b)

Figure 14. (a) In-cylinder pressure; (b) HRR vs. $G+E$ fraction by energy content.

\section{Conclusions}

The following conclusions can be drawn from the presented analyses:

- Blending crude glycerol with ethanol at a volumetric ratio of 1:1 (50/50\%) is a reasonable way to burn large amounts of glycerol in reciprocating internal combustion engines with diesel fuel pilot for self-ignition. Glycerol-ethanol blends also provide mixture stability during their storage.

- The proposed injection system consisting of two high pressure injectors with in-cylinder direct injection can be successfully applied to the engine for effective combustion of glycerol-ethanol blends.

- Preliminary investigation on engine exhaust toxic emissions shows that both NOx, UHC and CO are at satisfactory levels in comparison to emissions from diesel fueled engines.

- The most interesting issue in the toxic emissions was the significant decrease in smoke with increase in glycerol-ethanol blend in the total fuel charge injected into the engine cylinder. As found smoke was produced from combustion of the diesel fuel pilot. Blend of glycerol and ethanol reduced smoke several times from 40 to $3 \mathrm{mg} / \mathrm{cycle}$. This ratio was higher than diesel fuel decrease ratio from 22 to $9.5 \mathrm{mg} /$ cycle. As concluded, it was caused by the oxygen content in the $G+E$ blend.

- The only problem reported was the combustion got longer with an increase in $G+E$ content in the total fuel injected into the cylinder. Under fixed injection timings, it caused the diffusion combustion phase to shift far away from TDC location. As result, the thermal efficiency decreased. 
Plans for further research include the following: the problem with lengthening combustion can be improved by optimizing the geometry of the combustion chamber, mainly shape of the piston crown, that limit proper spraying and atomization of the $G+E$ dose. Therefore, it is planned to do research with other piston shapes, in-cylinder swirling and various injection angles into the cylinder.

Author Contributions: Conceptualization, M.G. and M.P.; methodology, M.G. and S.S.; Tests, M.G. and M.P.; software, M.G.; formal analysis, S.S. and M.S.; writing and draft preparation, S.S. and M.S.; writing and editing, S.S. All authors have read and agreed to the published version of the manuscript.

Funding: This research received no external funding.

Conflicts of Interest: The authors declare no conflict of interest.

\section{References}

1. Presciutti, A.; Asdrubali, F.; Baldinelli, G.; Rotilia, A.; Malavasi, M.; Di Salvia, G. Energy and exergy analysis of glycerol combustion in an innovative flameless power plant. J. Clean. Prod. 2018, 172, 3817-3824. [CrossRef]

2. Brock, D.; Koder, A.; Rabl, H.-P.; Touraud, D.; Kunz, W. Optimising the biodiesel production process: Implementation of glycerol derivatives into biofuel formulations and their potential to form hydrofuels. Fuel 2020, 264, 116695. [CrossRef]

3. Asuquo, G.; Toronjo, D.; Sastri, B.; Kouch, C. Crude Glycerol as Cost-Effective Fuel for Combined Heat and Power to Replace Fossil Fuels; Department of Energy: Washington, DC, USA, 2011.

4. Quispe, C.A.; Coronado, C.R.; Carvalho, J.A. Glycerol: Production, consumption, prices, characterization and new trends in combustion. Renew. Sustain. Energy Rev. 2013, 27, 475-493. [CrossRef]

5. Gupta, M.; Kumar, N. Scope and opportunities of using glycerol as an energy source. Renew. Sustain. Energy Rev. 2012, 16, 4551-4556. [CrossRef]

6. Available online: http://www.met.reading.ac.uk/ \{\{sws04cdw/viscosity_calc.html (accessed on 31 August 2020).

7. Available online: https://www.engineeringtoolbox.com/ethanol-dynamic-kinematic-viscosity-temperaturepressure-d_2071.html?vA=40\&degree=C\# (accessed on 31 August 2020).

8. Sliwinski, K.; Marek, W. The use of glycerin as motor fuel. Combust. Engines 2019, 178, 166-172.

9. Ferreira, A.G.M.; Egas, A.P.V.; Fonseca, I.M.A.; Costa, A.C.; Abreu, D.C.; Lobo, L.Q. The viscosity of glycerol. J. Chem. Thermodyn. 2017, 113, 162-182. [CrossRef]

10. Zhu, M.; Zhang, Z.; Zhang, Y.; Setyawan, H.; Liu, P.; Zhang, D. An experimental study of the ignition and combustion characteristics of single droplets of biochar-glycerol-water slurry fuels. Proc. Combust. Inst. 2017, 36, 2475-2482. [CrossRef]

11. Queirós, P.; Costa, M.; Carvalho, R.H. Co-combustion of crude glycerin with natural gas and hydrogen. Proc. Combust. Inst. 2013, 34, 2759-2767. [CrossRef]

12. Bohon, M.D.; Metzger, B.A.; Linak, L.P.; King, C.J.; Roberts, L.W. Glycerol combustion and emissions. Proc. Combust. Inst. 2011, 33, 2717-2724. [CrossRef]

13. Roberts, L.W. Crude Glycerol as Cost-Effective Fuel for Combined Heat and Power to Replace Fossil Fuels, DOE Final Technical Report. 2011. Available online: https://www.osti.gov/servlets/purl/1053951 (accessed on 31 October 2012). [CrossRef]

14. Coronado, C.R.; Carvalho, J.A., Jr.; Quispe, C.A.; Sotomonte, C.R. Ecological efficiency in glycerol combustion. Appl. Therm. Eng. 2014, 63, 97-104. [CrossRef]

15. Samoilov, V.O.; Borisov, R.S.; Stolonogova, T.I.; Zarezin, D.P.; Maximov, A.L.; Bermeshev, M.V.; Chernysheva, E.A.; Kapustin, V.M. Glycerol to renewable fuel oxygenates. Part II: Gasoline-blending characteristics of glycerol and glycol derivatives with $\mathrm{C}_{3}-\mathrm{C}_{4}$ alkyl(idene) substituents. Fuel 2020, 280, 118585. [CrossRef]

16. Fatimah, I.; Sahroni, I.; Fadillah, G.; Musawwa, M.M.; Meurah, T.I.M.; Muraza, O. Glycerol to Solketal for Fuel Additive: Recent Progress in Heterogeneous Catalysts. Energies 2019, 12, 2872. [CrossRef]

17. Rodrigues, A.; Bordado, J.C.; Galhano dos Santos, R. Upgrading the Glycerol from Biodiesel Production as a Source of Energy Carriers and Chemicals-A Technological Review for Three Chemical Pathways. Energies 2017, 10, 1817. [CrossRef] 
18. Stenhede, T. Combined Technologies Wärtsilä Power Plants; International Seminar on Gasification: Malmo, Sweden, 2008; Available online: http:/www.sgc.se/ckfinder/userfiles/files/SGC193.pdf (accessed on 10 October 2008).

19. Grab-Rogaliński, K.; Szwaja, S. The Possibility of Use a waste Product of Biofuels Production-Glycerol as a fuel to the Compression Ignition Engine. J. Kones 2016, 23, 157-164.

20. Lábaj, J.; Barta, D.; Lenhard, R. CFD simulation of glycerol combustion in diesel engine. In Colloquium Fluid Dynamics 2008; Institute of Thermomechanics AS CR v.v.i.: Prague, Czech Republic, 2008; pp. 35-50. ISBN 978-80-87012-14-7.

21. Oprescu, E.E.; Dragomir, R.E.; Radu, E.; Radu, A.; Velea, S.; Bolocan, I.; Stepan, E.; Rosca, P. Performance and emission characteristics of diesel engine powered with diesel-glycerol derivatives blends. Fuel Process. Technol. 2014, 126, 460-468. [CrossRef]

22. Eaton, S.J.; Harakas, G.N.; Kimball, R.W.; Smith, J.A.; Pilot, K.A.; Kuflik, M.T.; Bullard, J.M. Formulation and Combustion of Glycerol-Diesel Fuel Emulsions. Energy Fuels 2014, 28, 3940-3947. [CrossRef]

23. Beatrice, C.; Di Blasio, G.; Guido, C.; Cannilla, C.; Bonura, G.; Frusteri, F. Mixture of glycerol ethers as diesel bio-derivable oxy-fuel: Impact on combustion and emissions of an automotive engine combustion system. Appl. Energy 2014, 132, 236-247. [CrossRef]

24. Munsin, R.; Laoonual, Y.; Jugjai, S.; Matsuki, M.; Kosaka, H. Effect of glycerol ethoxylate as an ignition improver on injection and combustion characteristics of hydrous ethanol under CI engine condition. Energy Convers. Manag. 2015, 98, 282-289. [CrossRef]

25. McNeil, J.; Day, P.; Sirovski, F. Glycerine from biodiesel: The perfect diesel fuel. Process Saf. Environ. Prot. 2012, 90, 180-188. [CrossRef]

26. Grab-Rogaliński, K.; Szwaja, S. The combustion properties analysis of various liquid fuels based on crude oil and renewables. Iop Conf. Ser. Mater. Sci. Eng. 2016, 148, 012066. [CrossRef]

27. Chwist, M.; Gruca, M.; Pyrc, M.; Szwaja, M. By-products from thermal processing of rubber waste as fuel for the internal combustion piston engine. Combust. Engines 2020, 181, 11-18.

28. Lapuerta, M.; Rodríguez-Fernández, J.; García-Contreras, R. Effect of a glycerol-derived advanced biofuel -FAGE (fatty acid formal glycerol ester)- on the emissions of a diesel engine tested under the New European Driving Cycle. Energy 2015, 93, 568-579. [CrossRef]

29. Available online: https://www.avl.com/zh/-/avl-smoke-meter (accessed on 31 August 2020).

30. Zeldovich, Y.B. The oxidation of nitrogen in combustion explosions. Acta Phys. Ussr 1946, 21, 577-628.

Publisher's Note: MDPI stays neutral with regard to jurisdictional claims in published maps and institutional affiliations.

(C) 2020 by the authors. Licensee MDPI, Basel, Switzerland. This article is an open access article distributed under the terms and conditions of the Creative Commons Attribution (CC BY) license (http://creativecommons.org/licenses/by/4.0/). 